Accepted version of Larsson, S., Dahlgren, M. A., Walters, S., Boud, D and Sork, T. J. (2005).

Confronting globalization: learning from intercontinental collaboration, Innovations in Education

and Training International, 42, 1, 63-73.

\title{
Confronting Globalisation: Learning from intercontinental collaboration
}

Staffan Larsson and Madeleine Abrandt Dahlgren

Linköping University, Sweden

Shirley Walters

University of the Western Cape, South Africa

David Boud

University of Technology, Sydney, Australia

Thomas J. Sork

The University of British Columbia, Canada

\section{Introduction}

Higher education institutions are responding to the globalisation of national economies in a host of ways, including moving into other countries in virtual or actual mode and competing for a share of the local market. Programs developed within one academic culture are often exported to another or students are imported from another culture into local programs. The emerging Internet technology has supported this aspect of globalisation. Whereas internationalisation of higher education has a long history and was often based on the quasi-charitable notion of helping students from less welldeveloped higher education systems, more recently it has been based on an explicitly economic 
model involving the commodification of knowledge. Higher education is more and more considered as part of the growing service industry in this case producing "export products". One implication of these practices is that such programs are not necessarily meeting the needs and concerns of students, either those who are home-based or those who travel to study.

Historically, higher education from the start has been international. It was during the $17^{\text {th }}$ century that the nation states of Europe took control of the universities and developed their own unique higher education systems (Neave, 2001). The links between colonial control and education have been well known for a long time. For example, in the $17^{\text {th }}$ century when Sweden occupied what is now Estonia and what is now the most southern part of Sweden, the universities of Tartu and Lund were founded as a way of fostering Swedish mores amongst the elite and thus connect them to the occupier. Contemporary examples of the kind of exportation of curricula described above can be found among Australian, British and North American universities - as new forms of domination. There are now many examples of such universities providing 'packaged' courses in other countries, which, even when delivered by local personnel, take little account of the context in which they operate. Forms of open and distance learning offered around the world by institutions in English-speaking developed nations might, as Edwards and Usher (2000) claim, constitute an invasion that colonises and denies local culture and knowledge and underestimates learners. This can lead to what has been described as the 'McDonaldisation' of education (Smith, 2002).

This pattern of domination is not necessarily only imposed, but can be supported by demands from students who want competitive degrees from prestigious foreign universities. An 
historical example of this from British colonialism is when African students resisted curricula that were 'adapted' to the African context because they perceived as inferior any deviations from British academic standards and curriculum (Ball, 1984). It is also fostered in places such as Hong Kong that require programs offered by overseas universities to be identical to those offered in the home country. The cultural and economic hegemony of powerful nations will continue to feed this complex relationship between prestigious foreign programs that educate for another context and those which are less prestigious but locally focused.

Technology is making it easier to distribute learning across national boundaries. In an appraisal of the globalisation of higher education, Sadlak (1998) noted that more than 1 million students are enrolled in online courses. Castells (1996) as well as Edwards (2002) describes an emerging network society, where economic and cultural domination is related to the power of global networks. Within the context of higher education, technology can undermine or enhance the possibilities to defend local or national interests. The economically and technologically sophisticated have great potential to increase their domination mediated by this new technology. However, within countries there has also been a wave of virtual universities and programs, some of which have been based on collaboration between higher education institutions within a country and potentially strengthening higher education nationally (Karran \& Pohjonen, 2000). In countries such as Australia—which has an explicit competition policy—universities have operated in direct competition with one another in both domestic and overseas markets. The high number of international students in some universities has made some aware of the differences in academic cultures, and the need to negotiate interculturally (Cadman, 2000, p. 487-8).

Are there alternatives to models of domination and commodification? Korsgaard (1997) 
writes that globalisation is a two-edged sword. It not only enhances patterns of domination, it also: 'opens up new possibilities for a democratic influence on essential common issues' (p.23). Are there reasons why such alternatives have been difficult to develop? This paper presents research that analyses an example of a radically different approach to the use of new technology and the emerging network society in higher education. It is deliberately based on co-operation amongst universities from different parts of the world. We describe and analyse our experiences in developing a graduate degree program across four continents. This has involved four universities collaborating to offer an online Intercontinental Master's in Adult Learning and Global Change. The partner institutions are The University of Western Cape (UWC) in South Africa, Linköping University (LiU) in Sweden, University of British Columbia (UBC) in Canada and the University of Technology, Sydney (UTS) in Australia. Development of the program has been based on the principle of deliberations amongst equal partners who challenge an export model of education and who straddle the 'North-South' divide. Cross-country collaboration do exist, but often on unequal term, i.e. some university takes the role of being the base, the awarding body and where students are enroled (Hodgkinson \& Holland, 2002). However, the close and equal collaboration as in our case creates advantages as well as problems as our story will show

The focus of the paper is on the planning phase of the program that highlights what it means to develop such a program across differences in economic conditions, regulations and academic cultures. It is based on a case description of a practice that highlights the tensions between the local, national and global and how it frames human agency (Marginson, 2002). The first cohort of students' experiences of the programme has been analysed, but will be published separately (Abrandt Dahlgren et al. 2003). 


\section{The case}

The basic approach to developing the program was to negotiate its content and delivery among four equal partners. The planning started in 1998 and the first group of students started in 2001 . The Intercontinental Master's offers global perspectives on learning in cross-cultural environments. Courses are taught in collaboration amongst staff in the field of adult education from the partner universities. Students are admitted through each of the four partner universities so each cohort represents a complex four-continent network. The program is offered part-time over two years. It is structured so that students move through a sequence of required courses with the same international group of students. This means that students from at least four different continents constitute the class - a 'world-class'.

The program encourages critical perspectives on globalisation and reflective and strategic practices. The aims of the program are to enable students:

to learn and teach globally and use global technologies

to understand knowledge-based societies and the implications for learning

to develop an understanding of globalisation discourses, and develop cultural sensibilities and sensitivities

to develop equity perspectives on learning, and engage in reframing their own professional practices

to establish a global community of adult learning practitioners, and challenge orthodoxies in adult education practice.

The core of the pedagogical practice of the program emphasises intercontinental group work among 
students using examples from their every day life as educational content for analysis and to make comparisons between different contexts. Each course within the program includes tasks in which students collaborate across countries, and activities that draw extensively on resources from the different settings in which students operate.

The construction of the program has taken place by the planning team - the authors of this paper-through face-to-face meetings every six months rotated among the participating continents. The nature of the program, as an attempt at global collaboration amongst equal partners, has meant that inevitable tensions and contradictions have confronted the team. The focus of this paper is, firstly, on the structural constraints and possibilities that have become apparent and, secondly, on the actors' ways of dealing with these.

\section{Method}

\section{Theoretical Framework}

Concepts derived from two theoretical perspectives have inspired the present paper. The first is Giddens' (1984) concepts of 'structure' and 'agency'. The second is the notion of 'frame-factors' developed by Dahlöf and elaborated by Lundgren $(1985,1994,1999)$. Both perspectives focus on structures that are simultaneously constraining and full of possibilities. Giddens presents a view where structures are composed of situated actors engaged in social interaction pursuing their individual and collective interests. It is through this enacted conduct that structures are both maintained and changed. Changes in structures can be the result of conscious decisions made by the agents, but changes can also result from less conscious processes, such as adjustment and adaptation. Intended actions can also lead to unintended consequences, which in turn can have 
major impacts on the system. In frame-factor theory educational procedures are seen as formed by factors like administrative frames and material resources within which social relationships are produced and reproduced in social interaction. The actors' perceptions of how these frame-factors enable and constrain agency largely determine the shape and substance of programs.

In this project, the structures the actors operate within become very complex. Each partner institution has its own rules, traditions and convictions about academic rigor; its own bureaucratic structures and accountability frameworks; its own concerns about access and equity; its own terminology, methods and schedules for organising academic work; and its own financial structures and policies. The processes of implementing a collaboratively planned educational program are thus processes of shaping new structures through negotiation. The negotiations become a means for making our tacit and taken-for-granted understandings visible and for increasing our discursive consciousness of our individual institutional practices.

\section{Research Design}

The data sources on which we draw include detailed minutes of planning meetings, records of email conversations, interviews with course convenors and others involved in planning, and diary notes of the key actors. Since the researchers are also the main objects of research, their own reconstructions of the process supplement the documents mentioned above. The study could be presented as a participant observation project where all participants are both researchers and objects of research. However, key data are also the structures and regulations that are not influenced by the researchers. The processes of analysis and construction of narrative accounts have gone through several iterations to reach a negotiated consensus. 
The researchers/planners agreed on a joint theoretical and conceptual framework for the analysis. We agreed that data were to be analysed in critical and self-reflective ways and the conceptual pair 'structure' and 'agency' as well as 'frame factors' were to constitute the means of analysis in the jointly constructed narrative.

\section{Results}

The analysis reveals a number of dominant structural obstacles and patterns of how these were surmounted during the processes. Four areas reflect substantive differences among the collaborating universities:

(1) local decision-making processes.

(2) systems for examinations and grading;

(3) financial conditions; and

(4) information technology—in particular, the realities and possibilities for accessing the web.

\section{Local decision-making}

It is a great challenge for contemporary structures in higher education to have a common program approved by four partners in four countries. Frame factors here are national regulations; the idiosyncrasies of local university bureaucracies; and local academic cultures. In this context we want to highlight three problems with which we had to deal. The first was the meaning of a masters degree: a thesis was required as a necessary ingredient in two cases (LiU and UWC), but the other universities had the option to choose between a masters degree by thesis and a masters degree by coursework, and preferred the latter. This led to a decision that the program options should have 
some flexibility and we introduced local options that constituted $25 \%$ of the program. By deciding this, the obstacle of different conceptions regarding the required structure and content of a masters' program was overcome by reducing integration of the content. Of course, accommodating local variations in program requirements also means that staff at the two universities that require theses have a higher supervision load than staff at the coursework-only universities. This may lead to other problems as program enrolment increases in subsequent years.

The second problem was local requirements for texts constituting the basis for approving the program. The intercontinental steering group negotiated the program through some very difficult discussions. The underlying assumption was that local administrations needed to accept our decisions without changing them in order to avoid an infinite negotiation process. The program was to some extent shaped by this adaptation to local expectations and norms including the content of curriculum outlines regarding how assessments and courses should be described and the details of reference material required. Basically, this lead to the production of texts that met the most detailed and demanding requirements. In this way, one university's discourse became more powerful than that of the others. The pattern of agency regarding this issue was to subordinate all partners to the requirements of one university. A benefit of this is that it forced all the partners to elaborate the curriculum in great detail producing a very clear and commonly held understanding. But the costs of this included a much longer planning cycle and some tense moments in negotiations when exasperated members of the planning team wondered if the program would ever materialise.

Thirdly, differences in the tempo and complexity of procedures at each university stood out as a very important frame-factor. In the Swedish case there were three levels of decision-making 
that had to be dealt with. Each accepted the program in due course. One important aspect here was the initial support from the highest level of decision-making. Canada had to push the approval of the program through eight levels of decision-making and 22 separate approvals. The internal decision-making processes did not move quickly enough to conform to the planned implementation timetable of the program. In part this was due to the elaborate approval process in Canada, but part was also due to uncertainty about the most expeditious path to take for approval of such an unusual undertaking. UBC had no history of online master's programs let alone one involving partner universities on three other continents. The result was that they could not recruit students for the first cohort. Eventually the program was approved and they recruited students for the second round. They therefore had to contribute to course development and teaching in the first round without having any students of their own. In Australia, navigating the six layers of decisionmaking committees was not so onerous because those involved in promoting the program had considerable knowledge of the internal accreditation process. Documentation was no less demanding but the sensitive stages could be predicted and strategies were available to deal with the inevitable queries. The various committees made no concessions to the difficulties of international collaboration and the kinds of queries raised were just the same as if the proponents had it within their power alone to make changes. UWC in South Africa has four levels of decision-making including one at the national level. Political work was done both nationally and institutionally beforehand which helped the bureaucratic processes proceed relatively smoothly.

The pattern of agency adopted regarding this issue was where one partner had to contribute in the first year of delivery without getting anything for their own students, because of their university's complicated and slow decision-making process. 
It is clear that the administrative structures of universities are not typically designed to accommodate complex, collaborative initiatives. This could be seen as an anachronism. The technological basis of the program as well as the emerging social practices of the planners transcended the boundaries of a local university as a unit that constructs its own rules. Strong values are linked to this autonomy, but it creates the kind of contradictions that we have experienced.

\section{Systems for examinations and grading}

One structure that we encountered early in planning the program was the fact that the four institutions operated with different systems for examinations and grading. Two of the institutions (LiU and UTS) applied a pass/fail system, while two institutions (UBC and UWC) required a graded system for assessment. Initially, we agreed on a common pass/fail system, but this was later discarded since it became an obstacle to the approval process. The partners had to comply with the regulations prevailing locally regarding assessment systems. The issue of assessment remained on the agenda throughout the entire planning phase. It led to repeated, thorough and somewhat painstaking discussions about criteria for assessment and grading, during which fragments of our different academic cultures and value systems were revealed. The effects of an elaborated grading system on the perceived value of the program were a key element in the discussion. It was argued that traditions played an important role, not least for the students. The outcome was somewhat over-determined, since these arguments also were supported by regulations.

The solution finally adopted was to introduce a common instrument for conversion of grades into the four different grading 'currencies'. This common instrument, which none of the 
partners had previously used, was the European Credit Transfer System (ECTS), a uniform scale of seven grades that enables students to transfer academic credits from one institution to another within Europe. The ECTS grading scale is based on the combined use of keywords and definitions intended to clarify the keywords. It turned out to be a solution that the partner universities could agree on and that also makes it possible for the institutions to issue a final degree that conforms to local norms and regulations.

\section{Financial conditions}

Early on it became evident that universities in different countries have completely different ways of funding programs. For example, in Sweden there are no tuition fees. Universities get financial resources from the state for a specified number of study places. Funding a specific program is then a matter of competing with other programs for these limited places, a micro-political process within departments and faculties. In Australia tuition fees finance master's programs. In South Africa and Canada programs are financed by a mix of state funding and tuition fees.

These differences constituted a considerable problem that could have hampered collaboration amongst the institutions. It is obvious that students for whom financial considerations are paramount would, if allowed, prefer to participate in the program through the Swedish university, since there would have been no tuition fees. The consequence of this would be that financial resources for the other universities to run the program would have been drained. Early in the discussions about the program, we considered the possibility of moving money amongst the universities, but ruled that out, on the expectation that it would be extremely difficult to accomplish. The solution was to keep finances separate and, in principle, only recruit students from our own 
continents. The partners were linked together by an agreement about the number of students that could be accepted at each university and the courses for which each partner would be responsible. It was up to each of the partners to cover their own costs for course development and teaching. The solution pattern here was to exclude financial issues from the integrative parts of our work with the program.

A consequence of this solution was substantial differences amongst partners regarding access to resources. South Africa had difficulties, not least since it was anticipated that their students needed more technological support because of their more restricted access to these facilities. UWC engaged in a series of efforts to locate external funding agencies that could assist. Eventually there was some success through the Swedish International Development Cooperation Agency. The solution pattern we found here was to concentrate on solving the problems for one specific partner in order to accomplish the general development of the program.

\section{Information technology: realities and possibilities for accessing the web}

The original idea of the program was to deliver the same curriculum at the four different institutions separately. This idea was eventually transformed into a distance learning program where the partners take turns teaching the different courses. One of the basic ideas was also that communication amongst the participants across continents should constitute an important ingredient of the program to serve the purpose of learning about global similarities and differences.

When shaping this structure, we were aware that the different conditions for technological resources and possibilities for accessing the web in different parts of the world had to be taken into consideration. The comparatively limited bandwidth of South Africa and the restricted economic 
resources of the South African students were, in this instance, the main issues to be overcome. Early in the planning, e-mail was considered as a possible medium for communication in the program. An analysis of the possibilities and shortcomings of this medium led the group to decide that a more flexible and sustainable medium was needed that allowed for administering the program and tracking students. At a planning meeting in Cape Town, the group had arranged to test an alternative course platform on the web. This event became an important reality check to the whole group when the enterprise failed, due to difficulties in getting access to the web. This incident led to serious doubts about whether it would be possible to use an entirely web-based medium for the program. After further consideration, the group decided to choose the web-based solution anyway, despite the limitations of the South African telecom system.

The solution finally applied was twofold and consisted of both adjustment and

reinforcement. On the one hand, the institutions with stronger technological resources adjusted to the weakest link in the chain by refraining from using working formats that were too technologically demanding. Simple text-based formats were to be used in the early years of the program. We agreed to avoid large files, video-conferencing, synchronous discussion and other devices that the medium can offer. On the other hand, the group simultaneously started to search for funding that could help supply South African students with computer equipment that could reinforce their position in the program. As access to bandwidth and equipment in South Africa improves, the program will introduce additional curricular elements that are possible on the web.

\section{Conclusions}

The challenges of constructing a fair collaboration across continents are key issues for the future. 
Information technology is already part of everyday communication and this technological base will change the way education is organised and distributed. It allows various possibilities, one of which is for universities to export their programs. A consequence of this is the strengthening of patterns of domination. For example, British, Australian or North American universities can export their programs to different parts of the world, without much adaptation to local needs or sensitivity to local cultures.

As becomes obvious from our analysis of an alternative, exporting programs seems easier in certain ways than creating new ones based on genuine collaboration. Collaboration of the kind we describe is a complex, sometimes painstaking process of understanding the conditions for working across the continents to create a fair program. The reward is learning amongst both planners and students as to what it means to teach and learn across different academic conditions globally. The co-operation of four universities, representing very different contexts, has the potential to surpass the frames of the local resources. This means access to a broader range of academic staff since the partnership creates a 'global pool' of experienced academics. It also has the consequence of transcending the limitations in curriculum development framed by local/national traditions and structures. Collaboration therefore provides opportunities to surpass the limitations of local resources and competencies that can often be marked by academic ethnocentrism. The intercontinental collaboration creates some new frames, producing other possibilities and constraints, than do locally constructed programs.

In this paper where the focus is on the planning process, it is clear that the potential inherent in a program idea is not always fully realised. The reason is to a great proportion due to the universities' rules and regulations. It is easy to agree with Folkestad and Haag (2002) in their 
conclusion that the problem with the limited success of on-line education is university policies. Previous research and policy in online education has underestimated the amount of efforts and commitment required by faculty who are to develop and deliver courses on line, the authors argue. The real reason that faculty adopts slowly to the quest for online education is instead the difficulties in overcoming university policies. In our transnational case this barrier is higher than normal, since the collaboration is so deep.

From the perspective of equality amongst partners, the outcome is mixed. At times, local regulations meant that the most restrictive university seemed to set the rules for the program. The grading question revealed that local rules cannot always be transcended, and this resulted in an outcome no one necessarily wanted. The problems we encountered in the planning process were mainly structural. Dealing with the diversity in key frame factors became a preoccupation of the planning group. The main problem was that none of the university structures were accommodating to collaboration across national boundaries.

Each university or national university system is constructed on the idea that they are operating in splendid isolation that has, until now, functioned fairly well. Autonomy is no doubt a value that is deeply embedded in the whole idea of universities and is thus defended by the academy. It is also a way to defend the local against 'McDonaldisation' of higher education. The national features have in fact been constructed on two rationales, firstly the needs of the nation state and, secondly, the need for uniformity in higher education within the nation. National homogeneity

made it easier to compare candidates in the meritocracy that was a key element in the $19^{\text {th }}$ century but also to move between institutions within the national system (Neave, 2001). The uniformity that was established did not allow much flexibility. At the same time, collaboration internationally 
was made difficult particularly by bureaucratic regulations. It is these regulations that paradoxically work against the forms of international collaboration that our experience shows to be very beneficial in strengthening local institutions for the challenges of globalisation.

Collaboration that uses new technological structures enables a different kind of knowledge —a knowledge that is developed through discussions across continents and across diverse conditions. A repertoire of sophisticated technologies exists which can create opportunities for global learning, but whether they are successful in doing so depends more on the model of collaboration adopted than on the specifics of individual course and program designs or the sparkle and flash of the delivery medium. As is evident from our experience, a collaborative rather than a competitive model is possible even though the complications, to varying degrees, make it difficult to realise all the possibilities evident in the original idea.

\section{References}

ABRANDT DAHLGREN, M., LARSSON, S., WALTERS, S. (2003) Making the invisible visible. On participation and communication in a web-based programme. Contribution to The ECER conference in Hamburg, sept. 2003

BALL, S. J. (1984). 'Imperialism, social control and the colonial curriculum in Africa'. In I. Goodson \& S. J. Ball (Eds.) Defining the Curriculum: Histories and Ethnographies. London: Falmer.

CADMAN, K. (2000) 'Voices in the Air': evaluations of the learning experiences of international postgraduates and their supervisors, Teaching in Higher Education, 5 (4), pp 475-491.

CASTELLS, M. (1996). The Information Age. Economy, Society and Culture. Volume 1: 
The Rise of the Network Society. Oxford: Blackwell.

EDWARDS, R. \& USHER, R. (2000). Globalisation and pedagogy. Space, place and

identity. London and New York: Routledge

EDWARDS, R. (2002). Distribution and interconnectedness. The globalisation of education. In

M.R. LEA \& K. NICOLL (Eds.) Distributed Learning. Social and cultural approaches to practice. London: RoutledgeFalmer.

FOLKESTAD, L.S. \& HAAG, S. (2002) Conflicting ideologies and the shift to e-learning. Paper presented at the Annual Meeting of the American Educational Research Association. New

Orleans, LA, April 1-5 2002

GIDDENS, A. (1984). The Constitution of Society: Outline of the theory of structuration.

Cambridge: Polity Press.

HODGKINSON, M., HOLLAND, J. (2002) Collaborating on the Development of

Technology Enabled Distance Learning: A Case Study. Innovations in Education and Teaching International, Vol. 39, No 2, pp 89 - 94.

KARRAN, T. \& POHJONEN, J. (2000). Responding to the Vision of the Information Society:

First Steps Towards a National Virtual University. A Policy Discussion Paper. Oulu:

Publications of the Open University 4, University of Oulu.

KORSGAARD, O. (1997) The Impact of Globalisation on Adult Education. In: WALTERS, S.

(ed.) Globalisation, Adult Education \& Training. London: Zed Books.

LUNDGREN, U.P. (1985). 'Frame factors and the teaching process'. In T. Husén \& Postlethwait

(Eds.) The International Encyclopedia of Education. Vol.4. Oxford: Pergamon Press.

LUNDGREN, U.P. (1994). 'Om begränsningars möjligheter'. In C. Gustafsson \& S. Selander 
(Eds.), Ramfaktorteoretiskt tänkande. Ped. Inst. Uppsala universitet.

LUNDGREN, U.P. (1999). 'Ramfaktorteori och praktisk utbildningsplanering'. Pedagogisk Forskning i Sverige. 4 (1), p. 31-41.

MARGINSON, S. \& RHOADES, G. (2002) Beyond national states, markets, and systems of higher education: a global agency heuristic. Higher Education, 43 pp 281-309.

NEAVE, G. (2001). The European dimension in higher education: an excursion into the modern use of historical analogues. In J. HUISMAN, P. MAASEN \& G. NEAVE (Eds.) Higher Education and the Nation State. The International Dimension of Higher Education. Amsterdam: Pergamon. pp 13-74.

SADLAK, J. (1998). 'Globalisation and concurrent challenges for higher education'. In P. SCOTT (Ed). The Globalisation of Higher Education. Buckingham. SRHE and the Open University Press, pp 100-107.

SMITH, R. (2002). 'Exporting an educational culture: a critical review of the role of donors to education in the South'. Paper presented at NERA's 30th Congress in Tallinn, Estonia, 7-9 March 2002. 